\title{
Spectroscopic Characterisation of Metal Complexes with Tetradentate Ligand
}

\author{
Sahdeo Kumar, Pawan K. Pandey, Navneet Sinha, Sudama Chaudhari \\ and Shivadhar Sharma*
}

Department of Chemistry, Magadh University, Bodh Gaya, 824234 India

*Corresponding author: sharma.shivadhar@gmail.com

Published online: 25 November 2018

To cite this article: Kumar, S. et al. (2018). Spectroscopic characterisation of metal complexes with tetradentate ligand. J. Phys. Sci., 29(3), 1-11, https://doi.org/10.21315/ jps2018.29.3.1

To link to this article: https://doi.org/10.21315/jps2018.29.3.1

\begin{abstract}
A Schiff's base containing tetradenticity N,N-bis-(3-hydroxyquinoxaline)2-carboxidine-1,8-diaminenaphthalene, henceforth abbreviated as NBHCN, has been prepared by condensation of two moles of 3-hydroxyquinoxaline-2-carboxaldehyde with one mole of 1,8-diaminonaphthalene. This Schiff's base has been made to undergo complexation with Co(II) and Ni(II) metal ions. On the basis of their elemental analysis and molar conductivity values, the complexes have been formulated as [M(NBHCN) $\left.X_{2}\right]$ where $X$ stands for water, pyridine and $\alpha$-picoline which act as secondary ligands. The comparison of infrared spectra of metal complexes with that of NBHCN (Schiff's base ligand) indicates its coordination through two azomethine nitrogen and two deprotonated hydroxyl oxygen atoms. Thus, the ligand acts as a bivalent tetradentate anionic one joining through four potential sites to the metal ions. The magnetic moments of Co(II) complexes have been found in the range of 4.90-4.91 Bohr Magnetone (BM) which is greater than three unpaired electrons in spin free octahedral complexes of Co(II) metal ion. The slightly excess value of magnetic moment of Co(II) complexes from $\mu_{s}=3.87 \mathrm{BM}$, where $\mu_{s}$ is magnetic moment due to spin-only motion, may be attributed to ${ }^{4} T_{1 g}$ ground state of ${ }^{4} F$ term of $d$-system in octahedral symmetry, being orbitally triply degenerate, makes sufficient contribution to the magnetic moment of the complexes. The octahedral symmetry of Co(II) complexes has further been confirmed by their electronic spectra which display three bands due to ${ }^{4} T_{\lg (F)} \rightarrow{ }^{4} T_{2 g(F)},{ }^{4} T_{\lg (F)} \rightarrow{ }^{4} A_{2 g(F)}$ and ${ }^{4} T_{\lg (F)} \rightarrow{ }^{4} T_{\lg (P)}$ spin-allowed transitions. The magnetic moment values of $\mathrm{Ni}(\mathrm{II})$ complexes have been found in the range of 3.0-3.2 BM which is also greater than its $m_{s}$ value of $2.818 \mathrm{BM}$, corresponding to two unpaired electrons under octahedral symmetry. The appearance of three bands in their electronic spectra due to ${ }^{3} A_{2 g} \rightarrow{ }^{3} T_{2 g},{ }^{3} A_{2 g} \rightarrow{ }^{3} T_{1 g(F)}$ and ${ }^{3} A_{2 g} \rightarrow{ }^{3} T_{1 g(P)}$ spin-allowed transitions is indicative of octahedral symmetry around $\mathrm{Ni}(\mathrm{II})$. Their $v_{2} / v_{1}$ values also support octahedral geometry
\end{abstract}


around metal ions and decrease in Racah parameters $B$ from free metal ions to complexes is indicative of appreciable covalent character in $M-L$ bonds.

Keywords: Macrocyclic ligand, tetradenticity, distorted octahedral, spectroscopic characterisation, tetradentate ligand

\section{INTRODUCTION}

Transition metal complexes of Schiff's base macrocycle have been of considerable interest in terms of structural complexity and biological functions. ${ }^{1,2}$ Tetradentate Schiff's base ligands are able to coordinate with many different metal ions forming stable compounds and some of these compounds have been recognised as oxygen carrier. ${ }^{3,4}$ The tetradentate Schiff's base complexes of transition metal ions have shown an exponential increase in inorganic catalysis for various organic preparations..$^{5-8}$ The importance of coordination compounds of multidentates Schiff's base is widely known in pharmaceutical (antitumor, antiviral, antituberculosis and antimicrobial) and industrial (analytical reagent, polymer, coatings and fluorescent material) fields. ${ }^{9-13}$ N-hetrocycles like quinoxaline, quinozoline and their analogues are important hetrocycles that are present in many naturally occurring alkaloids and possess interesting pharmacological activities like antihypertensive, analgesic, anti-inflammatory, anticancer and anti-HIV activities. ${ }^{14-18}$ The Schiff's bases containing quinoxaline units are also known to exhibit wonderful pharmacological properties. The literature, however, reveals that no work has been reported on the metal complexes of Schiff's base derived from quinoxalinealdehyde and naphthalene-1,8-diamine. Therefore, we report herein the synthesis and characterisation of the Schiff's base derived from 3-hydroxyquinoaxaline-2-carboxaldehyde and 1,8-diaminonaphthalene and its metals complexes with $\mathrm{Co}$ (II) and $\mathrm{Ni}$ (II) metal ions in which the tetradenticity of the ligand may lead to the formation of macromolecule type coordination compounds with interesting spectral data.

\section{EXPERIMENTAL}

All the chemicals used were of analytical grade. 3-hydroxyquinoxaline2-carboxaldehyde was procured from Merck (Hyderabad, India), whereas 1,8-diaminonaphthalene was procured from Nice (Patna, India). The ligand N,Nbis-(3-hydroxyquinoxaline)-2-carboxidine-1,8-diaminonaphthalene has been prepared by refluxing $2 \mathrm{mmol}$ of 3-hydroxyquinoxaline-2-carboxaldehyde and 1,8-diaminonaphthalene in the presence of $\mathrm{HCl}(\mathrm{pH}=3.6)$ for $5 \mathrm{~h}$, whereby a yellow precipitate appeared which was filtered on suction pump and it was recrystallised in ethanol. It is illustrated in Figure 1. 


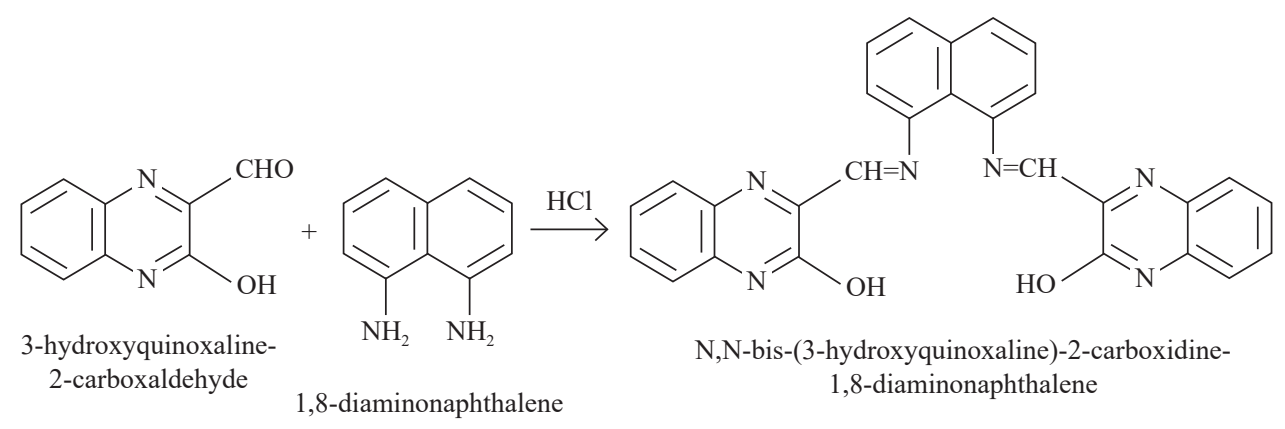

Figure 1: Illustration of ligand preparation.

The complexes were prepared by refluxing the ethanolic solution of the Schiff's base ligand, i.e., N,N-bis-(3-hydroxyquinoxaline)-2-carboxidine-1,8diaminonaphthalene (NBHCN) and ethanolic solution of metal chloride of $\mathrm{Co}(\mathrm{II})$ and $\mathrm{Ni}$ (II) taken in 1:1 molar ratio for about $30 \mathrm{~min}$ followed by the addition of the secondary ligands, pyridine $(2 \mathrm{mmol})$ or $\alpha$-picoline $(2 \mathrm{mmol})$ to it and was further refluxed for about $1 \mathrm{~h}$. The reacting mixture was stirred after cooling in ice for about 10 min whereby precipitate appeared was collected by filtration on suction pump and was washed by ethanol and water. It was dried in an air oven. The melting points of the compounds were determined on digital melting point apparatus Sturt SMP-40. The molar conductances of complexes were determined on a digital conductivity meter, MCD, HPG-3001 in dimethyl sulfoxide (DMSO) solution of $10^{-3} \mathrm{M}$ concentration. The microanalysis of ligand and complexes was carried out on a FLASH, EA-1112 for the determination of carbon, hydrogen and nitrogen contents of compounds. The contents of metals, $\mathrm{Co}$ and $\mathrm{Ni}$ in complexes were estimated gravimetrically. The infrared (IR) spectra of ligand and complexes were recorded on Fourier transform infrared spectrometer (FTIR) model RZX (Perkin Elmer) by KBR disc method. The electronic spectra of complexes in DMSO were recorded on Hitachi-330, UV-Vis-NIR Spectrometer. The magnetic susceptibility of complexes was determined on Gouty balance at room temperature.

\section{RESULTS AND DISCUSSION}

\subsection{Micro Analytical Data and Molar Conductivity}

The micro analytical data and molar conductivity of ligand and complexes are presented in Table 1. 
Table 1: Analytical, melting point, magnetic susceptibility, conductivity measurement of ligand $\mathrm{NBHCN}$ and its metal complexes.

\begin{tabular}{|c|c|c|c|c|c|c|c|c|}
\hline \multirow{2}{*}{ S. no. } & \multirow{2}{*}{ Compound } & \multirow{2}{*}{$\begin{array}{l}\text { Melting } \\
\text { point } \\
\left({ }^{\circ} \mathrm{C}\right)\end{array}$} & \multicolumn{4}{|c|}{$\%$ Analysis found / (calculated) } & \multirow{2}{*}{$\begin{array}{c}\lambda_{\mathrm{m}} \\
\left(\mathrm{ohm}^{-1} \mathrm{~cm}^{2}\right. \\
\left.\mathrm{mol}^{-1}\right)\end{array}$} & \multirow{2}{*}{$\begin{array}{c}\mu \\
(\mathrm{BM})\end{array}$} \\
\hline & & & M & $\mathrm{C}$ & $\mathrm{H}$ & $\mathrm{N}$ & & \\
\hline 1. & Ligand[NBHCN] & $175^{\circ} \mathrm{C}$ & - & $\begin{array}{c}71.76 \\
(71.48)\end{array}$ & $\begin{array}{c}3.62 \\
(3.83)\end{array}$ & $\begin{array}{c}17.56 \\
(17.88)\end{array}$ & - & - \\
\hline 2. & {$\left[\mathrm{Co}(\mathrm{NBHCN})\left(\mathrm{H}_{2} \mathrm{O}\right)_{2}\right]$} & $280^{\circ} \mathrm{C}$ & $\begin{array}{c}10.26 \\
(10.48)\end{array}$ & $\begin{array}{c}59.87 \\
(59.68)\end{array}$ & $\begin{array}{c}3.32 \\
(3.55)\end{array}$ & $\begin{array}{c}14.76 \\
(14.92)\end{array}$ & 15 & 4.91 \\
\hline 3. & {$\left[\mathrm{Co}(\mathrm{NBHCN})(\mathrm{Py})_{2}\right]$} & $288^{\circ} \mathrm{C}$ & $\begin{array}{c}8.40 \\
(8.61)\end{array}$ & $\begin{array}{c}66.89 \\
(66.56)\end{array}$ & $\begin{array}{c}3.62 \\
(3.79)\end{array}$ & $\begin{array}{c}16.18 \\
(16.34)\end{array}$ & 17 & 4.90 \\
\hline 4. & {$\left[\mathrm{Co}(\mathrm{NBHCN})(\alpha-\mathrm{Pico})_{2}\right]$} & $290^{\circ} \mathrm{C}$ & $\begin{array}{c}8.06 \\
(8.27)\end{array}$ & $\begin{array}{c}63.59 \\
(67.32)\end{array}$ & $\begin{array}{c}4.00 \\
(4.20)\end{array}$ & $\begin{array}{c}15.48 \\
(15.70)\end{array}$ & 16 & 4.90 \\
\hline 5. & {$\left[\mathrm{Ni}(\mathrm{NBHCN})\left(\mathrm{H}_{2} \mathrm{O}\right)_{2}\right]$} & $272^{\circ} \mathrm{C}$ & $\begin{array}{c}10.11 \\
(10.32)\end{array}$ & $\begin{array}{c}59.96 \\
(59.78)\end{array}$ & $\begin{array}{c}3.25 \\
(3.55)\end{array}$ & $\begin{array}{c}14.79 \\
(14.92)\end{array}$ & 15 & 3.20 \\
\hline 6. & {$\left[\mathrm{Ni}(\mathrm{NBHCN})(\mathrm{Py})_{2}\right]$} & $278^{\circ} \mathrm{C}$ & $\begin{array}{c}8.32 \\
(8.48)\end{array}$ & $\begin{array}{c}66.88 \\
(66.66)\end{array}$ & $\begin{array}{c}3.62 \\
(3.80)\end{array}$ & $\begin{array}{c}16.16 \\
(16.37)\end{array}$ & 18 & 3.00 \\
\hline 7. & {$\left[\mathrm{Ni}(\mathrm{NBHCN})(\alpha-\mathrm{Pico})_{2}\right]$} & $290^{\circ} \mathrm{C}$ & $\begin{array}{c}8.00 \\
(8.14)\end{array}$ & $\begin{array}{c}67.68 \\
(67.41)\end{array}$ & $\begin{array}{c}4.08 \\
(4.21)\end{array}$ & $\begin{array}{c}15.61 \\
(15.73)\end{array}$ & 17 & 3.01 \\
\hline
\end{tabular}

The conductivity of complexes lies in the range of $15-18 \mathrm{ohm}^{-1} \mathrm{~cm}^{2} \mathrm{~mol}^{-1}$ which is indicative of non-electrolytic nature of complexes. ${ }^{19,20}$ On the basis of elemental analysis and conductance values, complexes were formulated as $\left.\left[\mathrm{M}(\mathrm{NBHCN}) \mathrm{X}_{2}\right)\right]$ where NBHCN $=$ Schiff's base ligand and $\mathrm{X}=\mathrm{H}_{2} \mathrm{O}$, pyridine and $\alpha$-picoline.

\subsection{IR Spectra}

The important and significant IR bands before and after complexation have been detected and assigned. The free ligand displays two broad bands at $3430 \mathrm{~cm}^{-1}$ and $3420 \mathrm{~cm}^{-1}$ which may be assigned to H-bonded $v_{\mathrm{OH}}$ of enolic tautomeric form and $\mathrm{H}$-bonded $v_{\mathrm{N}-\mathrm{H}}$ in amide tautomeric form of the three ligand. ${ }^{21,22}$ It shows that the free ligand exists in tautomeric form which is further confirmed by the absence of medium band at $1690 \mathrm{~cm}^{-1}$ due to $v_{\mathrm{c}=0}$ of ketoform. ${ }^{23-26}$ In the IR spectra of the complexes, all these three bands disappear which indicates the dehydrogenation of phenolic $\mathrm{OH}$ group and coordination through deprotonated oxygen. ${ }^{27-30}$ The azomethine group $v_{\mathrm{CH}=\mathrm{N}}$ absorbs sharply at $1600 \mathrm{~cm}^{-1}$ in the IR spectra of free ligand. ${ }^{31,32}$ The other sharp band at $1520 \mathrm{~cm}^{-1}$ is fairly assigned to endocyclic $v_{\mathrm{C}=\mathrm{N}}$ vibration of quinoxaline ring. The former band shifts to higher frequency and appears at $1640-1650 \mathrm{~cm}^{-1}$ while the second band remains intact at $1590 \mathrm{~cm}^{-1}$ in 
the spectra of complexes. It clearly predicts that azomethine nitrogen is involved in the coordination. The endocyclic nitrogen does not participate in coordination to the metal ions. ${ }^{33-35}$ The abnormal increase in $v_{\mathrm{C}=\mathrm{N}}$ after coordination to the metal ions may be attributed to the extensive delocalisation of $\pi$-electrons in fully conjugated Schiff's base ligand. Thus, the IR spectra of complexes on comparison with that of free ligand reveals that the ligand coordinates through two azomethine nitrogen and two deprotonated phenolic $\mathrm{OH}$ groups. The coordination through nitrogen and oxygen is further confirmed by the appearance of two new bands, i.e., at $470-460 \mathrm{~cm}^{-1}$ and at $430-420 \mathrm{~cm}^{-1}$ which may be assigned to $v_{\mathrm{M}-\mathrm{O}}$ and $v_{\mathrm{M}-\mathrm{N}}$, respectively. ${ }^{36}$ The appearance of two new bands at $3390 \mathrm{~cm}^{-1}$ and $900 \mathrm{~cm}^{-1}$ in spectra of complexes no. 1 and 4 as in the table may be due to stretching and rocking mode of vibration of coordinated water. ${ }^{37}$ The appearance of new bands at $760 \mathrm{~cm}^{-1}$ in IR spectra of complexes no. 2 and 5, and at $765 \mathrm{~cm}^{-1}$ in complexes no. 3 and 6 show the presence of pyridine and $\alpha$-picoline within the coordination sphere of these complexes. ${ }^{38}$

\subsection{Magnetic and Electronic Spectra}

The magnetic moments of complexes have been given in Table 1. The Co(II) complexes exhibit magnetic moment of 4.90-4.91 BM. These values are higher than the values for three unpaired electrons in high spin octahedral complexes, which may be due to orbital contribution from triply degenerate ground state ${ }^{4} T_{1 g}$.

These complexes display three bands, in their electronic spectra, which may be assigned as below:

$$
\begin{aligned}
& v_{1}=7100-7200 \mathrm{~cm}^{-1}={ }^{4} \mathrm{~T}_{1 \mathrm{~g}(\mathrm{~F})} \rightarrow{ }^{4} \mathrm{~T}_{2 \mathrm{~g}(\mathrm{~F})} \\
& v_{2}=14980-15250 \mathrm{~cm}^{-1}={ }^{4} \mathrm{~T}_{1 \mathrm{~g}(\mathrm{~F})} \rightarrow{ }^{4} \mathrm{~A}_{2 \mathrm{~g}(\mathrm{~F})} \\
& v_{3}=13220-14610 \mathrm{~cm}^{-1}={ }^{4} \mathrm{~T}_{1 \mathrm{~g}}(\mathrm{~F}) \rightarrow{ }^{4} \mathrm{~T}_{2 \mathrm{~g}}(\mathrm{P})
\end{aligned}
$$

The various crystal field parameters derived from electronic spectral bands of

\begin{tabular}{|c|c|c|c|c|}
\hline \multirow{2}{*}{ Compounds } & $10 \mathrm{Dq}$ & B & $\beta$ & \multirow{2}{*}{$v_{2} / v_{1}$} \\
\hline & $\left(\mathrm{cm}^{-1}\right)$ & $\left(\mathrm{cm}^{-1}\right)$ & $(\%)$ & \\
\hline$\left[\mathrm{Co}(\mathrm{NBHCN})\left(\mathrm{H}_{2} \mathrm{O}\right)_{2}\right]$ & 7884 & 463.75 & 52.23 & 2.11 \\
\hline$\left[\mathrm{Co}(\mathrm{NBHCN})(\mathrm{Py})_{2}\right]$ & 7970 & 498.00 & 48.66 & 2.114 \\
\hline$\left[\mathrm{Co}(\mathrm{NBHCN})(\alpha-\mathrm{Pico})_{2}\right]$ & 8028 & 537.00 & 44.63 & 2.12 \\
\hline
\end{tabular}
Co(II) complexes using Tanabe Sugano diagram are given in Table 2.

Table 2: Crystal field parameters of Co(II) complexes. 
The values of the various crystal field parameters are in good agreements with values reported for slightly distorted octahedral complexes of $\mathrm{Co}$ (II). ${ }^{39-41}$

The magnetic moment of $\mathrm{Ni}(\mathrm{II})$ complexes are found in between 3.0-3.2 BM. The value is greater than $\mu_{\mathrm{s}}(2.83 \mathrm{BM})$ corresponding to two unpaired electrons in octahedral Ni(II) complexes. This may be due to second order Zeeman effect, under which $\mu$ effective is given by $\mu_{e f f}=\mu_{s o}\left(1-\frac{4 \lambda}{10 D q}\right)$ as $\lambda$ for Ni(II), a d $\mathrm{d}^{8}$-system is negative $(-\mathrm{ve})$ and hence $\mu_{\text {eff }}$ becomes greater than $\mu_{\mathrm{s}}$ value. ${ }^{42}$

The electronic spectra of Ni(II) complexes display four bands which show strong tetragonal distortion in complexes due to which ${ }^{3} \mathrm{~T}_{2 \mathrm{~g}}$ and ${ }^{3} \mathrm{~T}_{1 \mathrm{~g}}$ of cubic field terms of ${ }^{3} \mathrm{~F}$ ground state term further undergo splitting and hence the assignment of bands may be given to the following spin allowed transitions.

$$
\begin{aligned}
& v^{1}=8900-8990 \mathrm{~cm}^{-1}={ }^{3} \mathrm{~B}_{1 \mathrm{~g}} \rightarrow{ }^{3} \mathrm{E}_{\mathrm{g}}(\mathrm{a}) \\
& v^{2}=11640-11690 \mathrm{~cm}^{-1}={ }^{3} \mathrm{~B}_{1 \mathrm{~g}} \rightarrow{ }^{3} \mathrm{~B}_{2 \mathrm{~g}} \\
& v^{3}=15200-15270 \mathrm{~cm}^{-1}={ }^{3} \mathrm{~B}_{1 \mathrm{~g}} \rightarrow{ }^{3} \mathrm{~A}_{2 \mathrm{~g}}(\mathrm{a}) \\
& v^{4}=16780-16820 \mathrm{~cm}^{-1}={ }^{3} \mathrm{~B}_{1 \mathrm{~g}} \rightarrow{ }^{3} \mathrm{E}_{\mathrm{g}}(\mathrm{b})
\end{aligned}
$$

On the basis of these bands, the values of various crystal field parameters like $\mathrm{Dq}_{(\mathrm{x}, \mathrm{y})}, \mathrm{Dq}_{(\mathrm{z})}, \mathrm{D}_{\mathrm{s}}$ and $\mathrm{D}_{\mathrm{t}}$, the extent of distortion from octahedral symmetry were derived and values have been given in Table 3 below:

Table 3: Crystal field parameters of Ni(II) complexes.

\begin{tabular}{lcccc}
\hline \multirow{2}{*}{ Compound } & $\mathrm{Dq}_{(\mathrm{x}, \mathrm{y})}$ & $\mathrm{Dq}_{(\mathrm{z})}$ & \multicolumn{1}{c}{$\mathrm{D}_{\mathrm{s}}$} & \multicolumn{1}{c}{$\mathrm{D}_{\mathrm{t}}$} \\
\cline { 2 - 5 } & $\left(\mathrm{cm}^{-1}\right)$ & $\left(\mathrm{cm}^{-1}\right)$ & $\left(\mathrm{cm}^{-1}\right)$ & $\left(\mathrm{cm}^{-1}\right)$ \\
\hline$\left[\mathrm{Ni}(\mathrm{NBHCN})\left(\mathrm{H}_{2} \mathrm{O}\right)_{2}\right]$ & 1165 & 615.50 & 732 & 314 \\
{$\left[\mathrm{Ni}(\mathrm{NBHCN})(\mathrm{Py})_{2}\right]$} & 1164 & 618 & 736 & 312 \\
{$\left[\mathrm{Ni}(\mathrm{NBHCN})(\alpha-\mathrm{Pico})_{2}\right]$} & 1168 & 630.75 & 747.75 & 307.42 \\
\hline
\end{tabular}

The values of various crystal field parameters are in good agreements with the reported values for tetragonally distorted octahedral complexes of $\mathrm{Ni}(\mathrm{II}){ }^{43,44}$

\section{CONCLUSION}

The present study reveals that the Schiff's base NBHCN contains four potential sites for coordination to metal ions. Thus, it behaves as bianionic tetradentate coordinating through two azomethine nitrogen and two deprotonated phenolic 
oxygen. On the basis of magnetic moment values and electronic spectra of $\mathrm{Co}$ (II) and $\mathrm{Ni}(\mathrm{II})$, they are found to be octahedral with a little tetragonal distortion. The four coordinated sites of the ligand lie in XY plane while water, pyridine and $\alpha$-picoline are tagged along $Z$-axis causing distortion in octahedral symmetry. On the basis of Dt. values in $\mathrm{Ni}$ (II) complexes, the distortion power of $\mathrm{Z}$-axis ligands may be given in the following order: $\mathrm{H}_{2} \mathrm{O}>$ pyridine $>\alpha$-picoline. The tentative structure of complexes may be given as the following:

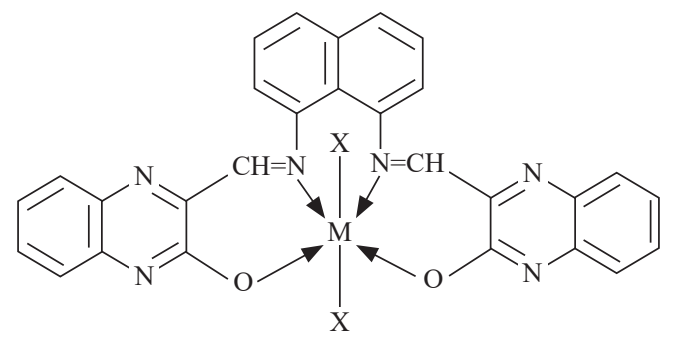

\section{ACKNOWLEDGEMENTS}

One of the authors, Mr. Sahdeo Kumar is thankful to University Grant Commission, New Delhi, India for awarding the Rajiv Gandhi National Fellowship (RGNF2014-15-SC-BIH-68680).

\section{REFERENCES}

1. Zanello, P. et al. (1982). Electrochemical behaviour of complexes of Cu(II) with 14-membered Saturated tetra-aza macrocycles. J. Chem. Soc. Dalton Trans., 893-897, https:// doi.org/10.1039/DT9820000893.

2. Prasad, R. N., Chaudhary, S. \& Jain, A. (2014). Synthesis and spectral studies of chromium(III) and iron(III) complexes of trioxodiazamacrocycles. J. Ind. Chem. Soc., 91, 137-141.

3. Floriani, A. \& Calderazzo, F. (1969). Oxygen adducts of Schiff's base complexes of cobalt prepared in solution. J. Chem. Soc. A, 946-953, https://doi.org/10.1039/J19690000946.

4. Rafat, M. S. et al. (2008). Synthesis and characterization of Ru(III) with chelating containing ONNO donor quadridentate Schiff bases. Spectrochim. Acta. A, 70, 898-906, https://doi.org/10.1016/j.saa.2007.10.005.

5. Yamada, S. (1999). Advancement in stereochemical aspects of Schiff base metal complexes. Coord. Chem. Rev., 190, 537-555, http://doi.org/10.1016/ S0010-8545(99)00099-5. 
6. Amirnasr, M. et al. (2002). Cobalt (II), nickel (II), zinc (II) complexes with bidentate, N, N'-bis( $\beta$-phenyl cinnamaldehyde)-1,2-diiminoethane Schiff base: Synthesis and structures. Polyhedr., 21, 2733-2742, https://doi.org/ 10.1016/S0277-5387(02)01277-9.

7. Knnan, S. \& Ramesh, R. (2006). Synthesis characterization catalytic oxidation and biological activity of ruthenium(III) Schiff base complexes derived from 3-acetyl-6-methyl-2H-pyran-2,4 (3H)-dione. Polyhedr., 25, 3095-3103, https://doi.org/10.1016/j.poly.2006.05.042.

8. Arunachalam, S., Priya, N. P. \& Meeran, H. S. (2014). Facile synthesis of $\mathrm{Ru}(\mathrm{II})$ Schiff base complexes: Spectral characterization and antimicrobial applications. J. Ind. Chem. Soc., 91, 53-61.

9. More, P. G., Bhalvankar, R. B. \& Pattor, S. C. (2001). Synthesis and biological activity of Schiff bases of aminothiazoles. J. Ind. Chem. Soc., $78,474-475$.

10. Jayabalakirishnan, C.\& Natrajan, K. (2001). Synthesis, characterization and biological activities of Ru(II) carbonyl complexes containing bifunctional tridentate Schiff bases. Synth. React. Inorg. Met. Org. Chem., 31, 983-995, https://doi.org/10.1081/SIM-100105255.

11. Ispir, E. et al. (2005). Synthesis and antimicrobial activity of new Schiff base having the SiOR group $\left(\mathrm{R}=\mathrm{CH}_{3}\right.$ or $\left.\mathrm{CH}_{2} \mathrm{CH}_{3}\right)$ and their transition metal complexes. Trans. Met. Chem., 30, 1042-1047, https://doi.org/10.1007/ s11243-005-6311-5.

12. Chohan, Z. H. et al. (2004). Antifungal cobalt (II), copper (II), nickel (II) and zinc (II) complexes of furanyl-thiobiphenyl-, pyrrolyl-, salicylyl-, and pyridyl- derived cephalexin. J. Enz. Inhib. Med. Chem., 19, 85-90, https://doi.org/10.1080/14756360310001650183.

13. Sari, N., Nartop, D. \& Logogul, E. (2009). Synthesis, characterization, conductivity and invesitigation of antimicrobial and fungus of magnetic polymer including Schiff bases. Asian J. Chem., 21, 2331-2339.

14. Alagarashami, V., Murugananthan, G. \& Porumal, R. V. (2003). Synthesis analgesic, anti- inflammatory and antibacterial activities of some novel, 2-methyl-3-substituted quinazolin-4(3H)-ones. Biol. Pharm. Bull., 26, 1711-1714, https://doi.org/10.1248/bpb.26.1711.

15. Alagarshami, V., Solomn, V. R. \& Murugan, M. (2007). Synthesis and pharmacological investigation of novel 4-benzyl-1-substituted-4H-[1,2,4,] triazolo[4,3a]quinazolin-5-ones as new class of $\mathrm{H}_{1}$-antihistaminic agents. Bio. Org. Med. Chem., 15, 4009-4015, https://doi.org/10.1016/j. bmc.2007.04.001. 
16. Hour, M. J. et al. (2000). 6-alkylamino and 2,3-dihydro-3-methoxy2-phenyl-4-quinazolinones and related compounds: Their synthesis, cytotoxicity and inhibition of tubulin polymerization. J. Med. Chem., 43, 4479-4487, https://doi.org/10.1021/Jm000151c.

17. Alagarashami, V. et al. (2007). Anti HIV, antibacterial and antifungal activities of some novel 2-methyl-3-(substituted methylamino)-(3H)quinazolin-4-ones. Ind. J. Pharm. Sci., 69, 304-307, https://doi.org/ 10.4103/0250-474X.33167.

18. Sahu, P. K. et al. (2015). Design, synthesis and synergistic antioxidant, antibacterial, antifungal activity of nitrogen hetrocycles. J. Ind. Chem. Soc., 92, 169-182.

19. Siddappa, K. et al. (2011). Synthesis spectral powder X-ray diffraction and antimicrobial studies of some transition metal(II) complexes of Schiff base derived from 3-[(2-hydroxy-6-methyl-quinolin-3-ylmethylene)-amino)]-2methyl-3H-quinazolin-4-one. Asian J. Chem., 23, 4511-4516.

20. Kumari, P., Prakash, S. \& Prakash, D. (2012). Synthesis and characterization of some hetrobinuclear Ni(II) Schiff base complexes. J. Ind. Chem. Soc., $89,19-23$.

21. Tumer, M. et al. (2008). Synthesis and characterization of Schiff base metal complexes: Their antimicrcibal, genotoxicity and electrochemical propesties. J. Coord. Chem., 61, 2935-2949, https://doi.org/10.1080/ 00958970801989902.

22. Mehta, B. H. \& Disale, S. D. (2012). Synthesis physicochemical characteristics and biological activity of $\mathrm{Ru}(\mathrm{III})$ Complexes with bidentate (N, O) Schiff bases. J. Ind. Chem. Soc., 89, 315-322.

23. Mamedev, V. A. et al. (2003). Fused nitrogen containing hetro cycles: III. 4.-oxo-1-phenyl-4,5-dihydroimidazo (1,5a) quinoxalines: A retro synthetic approach. Russ. J. Org. Chem., 39, 125-130, https://doi.org/ 10.1023/A:1023463117204.

24. Arunachalam, S. et al. (2010). Biocidal and catalytic efficiency of Ru (III) complexes with tridentate Schiff base ligands. Appl. Organomet. Chem., 24, 491-498.

25. Arunachalam, S. et al. (2010). Ru(III) tetradentate Schiff base complexes: Spectral catalytic and its biological efficacy. J. Coord. Chem., 63, 17951806, https://doi.org/10.1080/00958972.2010.487937.

26. Balasubramaniam, K. P. et al. (2007). Synthesis, spectral, catalytic and antimicrobial studies of $\mathrm{pph}_{3} / \mathrm{Asph}_{3}$ complexes of $\mathrm{Ru}(\mathrm{II})$ with dibasic tridentate O,N,S, donar ligands. Spectrochim. Acta A, 68, 50-54, https://doi.org/10.1016/j.saa.2006.10.049. 
27. Singh, N. K. \& Singh, S. B. (1993). Synthesis, characterization and biological properties of $\mathrm{Mn}(\mathrm{II}), \mathrm{Co}(\mathrm{II}), \mathrm{Ni}(\mathrm{II}), \mathrm{Cu}(\mathrm{II}), \mathrm{Zn}(\mathrm{II}) \mathrm{Cr}(\mathrm{III})$ and $\mathrm{Fe}(\mathrm{III})$ complexes with a new thiosemicarbazide derivative. Ind. J. Chem. Sect. A, 40, 1070-1075.

28. Rahman, F. et al. (2008). Synthetic, spectral, thermal and antimicrobial activity studies of some transition metal complexes derived from 2-hydroxy methylbenzaldehyde. J. Ind. Chem. Soc., 85, 381-386.

29. Ahuja, M. (2014). Synthetic and Biocidal studies on oxo vanadium complexes of substitued 2-pyrazolines having thienyle moiety. J. Ind. Chem. Soc., 91, 1277-1282.

30. Dey, D. et al. (2014). Synthesis and spectroscopic characterization of a dinudear nickel complex: A bio-relevant catalyst and its reactivity. J. Ind. Chem. Soc., 91, 1267-1276.

31. Paira, M. K. et al. (2013). Syntheses, spectral characterization, redox properties and DFT computations of $\left[\mathrm{MH}(\mathrm{CO})\left(\mathrm{PPH}_{3}\right)_{2}\right.$ (N-hetrocycle Schiff bases ${ }^{+}(\mathrm{M}=\mathrm{Ru}$ and Os $)$ and their applications to the synthesis of Ag nanoparticles. J. Ind. Chem. Soc., 90, 423-436.

32. Kumar, S. B. \& Mahendrasini, Z. (2013). Syntheses, characterization and structures of $\mathrm{Cd}(\mathrm{II})$ and $\mathrm{Zn}(\mathrm{II})$ pseudohalide complexes containing pyridyl pyrazole ligand. J. Ind. Chem. Soc., 90, 935-941.

33. Borras, J. et al. (2007). Crystal structures and spectroscopic propesites of $\mathrm{Cu}(\mathrm{II})$ bis (2-pyridyl carbonyl) amidechlorobenzoate complexes. Polyhedr., 26, 5009-5015, https://doi.org/10.1016/j.Poly.2007.07.019.

34. Suryawanshi, N. J. et al. (2013). Synthesis characterization of thermal electrical conductivity and biological studies of Schiff base metal complexes. J. Ind. Chem. Soc., 90, 1327-1333.

35. Patel, R. N. et al. (2012). Synthesis, characterization and bioactivities of new copper (II) complexes of N'-[(1E)-1H-pyrrol-2-ylmethylidene] pyridine-3-carbohydrazone. J. Ind. Chem. Soc., 89, 1085-1092.

36. Raman, N. (2008). Synthesis, spectral characterization electrochemical behaviour and antibacterial activity of mixed ligand $\mathrm{Cu}$ (II) and $\mathrm{Zn}$ (II) complexes of 3,4-substituted $\beta$-diketones with 2, 2-bipyridine. J. Ind. Chem. Soc., 85, 1082-1088.

37. Rani, R. et al. (2013) Spectroscopic characterization of some $\mathrm{Cu}(\mathrm{II})$ complexes. J. Ind. Chem. Soc., 90, 331-336.

38. Joseph, A., Joseph, B. \& Narayana, B. (2008). Complexes of Ag(I), Ti(I), $\mathrm{Zn}$ (II) Cd(II), Hg(II), Co(II), Ni(II), Ru(II), Pd(II), Ru(III), Rh(III), Pt(IV), 4-(pyridine-2-corboxylidineamino)-5-marcapto-1,2,4-triazole. J. Ind. Chem. Soc., 85, 479-484.

39. Singh, A. K. et al. (2011). Nephelauxatic effect of telluro ether complexes of Co(II), Ni(II) and Cu(II). Asian J. Chem., 23(10), 4347-4350. 
40. Vasudeva, R. K. et al. (2011). Spectrophotometric, determination of $\mathrm{Cu}$ (II) in biological samples by using 2-Acetyl furan thiosemicarbazone as chelating reagent. Asian J. Chem., 23(10), 4425-4429.

41. Raju, S. et al. (2012). Speciation of binary complexes of L-glutamic acid with $\mathrm{Co}$ (II), Ni (II), and $\mathrm{Cu}$ (II) in low dilectric media. J. Ind. Chem. Soc., 89, 57-62.

42. Rastogi, A. et al. (2010). Macrocyclic Ni(II) complexes of some polynucleating aza ligands. J. Ind. Chem. Soc., 87, 1053-1059.

43. Nakanoto, K. \& McCarthy, P. J. (1968). Spectroscopy and structure of metal chelate compounds. New York: John Wiley \& Sons.

44. Bhatnagar, P. \& Bhatnagar, M. K. (2012). Physico-chemical studies on mixed ligand complexs of $\mathrm{Mn}(\mathrm{II}), \mathrm{Fe}(\mathrm{II}), \mathrm{Co}(\mathrm{II})$, and Ni(III) with famotidine and some amino acids. J. Ind. Chem. Soc., 89, 1273-1278. 